\title{
The Long-Term Impact of Vaginal Surgical Mesh Devices in UK Primary Care: A Cohort Study in the Clinical Practice Research Datalink
}

\author{
Emily McFadden (iD ${ }^{\prime}$ \\ Sarah Lay-Flurrie ${ }^{1,2}$ \\ Constantinos Koshiaris ${ }^{\prime}$ \\ Georgia C Richards (D) ${ }^{1,3}$ \\ Carl Heneghan 1,3 \\ 'Centre for Evidence Based Medicine, \\ Nuffield Department of Primary Care \\ Health Sciences, University of Oxford, \\ Oxford, UK; ${ }^{2}$ EMEA Real World Methods \\ and Evidence Generation, IQVIA, \\ London, UK; ${ }^{3} \mathrm{Global}$ Centre on \\ Healthcare and Urbanisation, Kellogg \\ College, University of Oxford, \\ Oxford, UK
}

Correspondence: Emily McFadden Centre for Evidence Based Medicine, Nuffield Department of Primary Care Health Sciences, University of Oxford, Radcliffe Observatory Quarter,

Woodstock Road, Oxford, OX2 6GG, UK $\mathrm{Tel}+44 \quad 1865617940$

Email emily.mcfadden@phc.ox.ac.uk
Purpose: Stress urinary incontinence (SUI) and pelvic organ prolapse (POP) may be treated with surgical mesh devices; evidence of their long-term complications is lacking.

Patients and Methods: Rates of diagnoses of depression, anxiety or self-harm (composite measure) and sexual dysfunction, and rates of prescriptions for antibiotics and opioids were estimated in women with and without mesh surgery, with a diagnostic SUI/POP code, registered in the Clinical Practice Research Datalink (CPRD) gold database.

Results: There were 220,544 women eligible for inclusion; $74 \%(\mathrm{n}=162,687)$ had SUI, $37 \%(\mathrm{n}=82,123)$ had POP, and $11 \%(\mathrm{n}=24,266)$ had both. Women undergoing mesh surgery for SUI or POP had about 1.1 times higher rates of antibiotic use. Women with no previous history of the outcome, who underwent mesh surgery had 2.43 (95\% CI 2.19-2.70) and 1.47 (95\% CI 1.19-1.81) times higher rates of depression, anxiety, or self-harm, 1.88 (95\% CI 1.50-2.36) and 1.64 (95\% CI 1.02-2.63) times higher rates of sexual dysfunction and 1.40 (95\% CI 1.26-1.56) and 1.23 (95\% CI 1.01-1.49) times higher opioid use for SUI and POP, respectively. Women with a history of depression, anxiety and self-harm had 0.3 times lower rates of these outcomes with SUI or POP mesh surgery (HR for SUI 0.70 (95\% CI 0.67-0.73), HR for POP 0.72 (95\% CI 0.65-0.79)). Women with a history of opioid use who had POP mesh surgery had about 0.09 times lower rates (HR 0.91 (95\% CI 0.86-0.96)) of prescriptions. Negative control outcome analyses showed no evidence of an association between asthma consultations and mesh surgery in women with POP, but the rate was 0.09 times lower (HR 0.91 (95\% CI 0.87-0.94)) in women with SUI mesh surgery, suggesting that study results are subject to some residual confounding.

Conclusion: Mesh surgery was associated with poor mental and sexual health outcomes, alongside increased opioid and antibiotic use, in women with no history of these outcomes and improved mental health, and lower opioid use, in women with a previous history of these outcomes. Although our results suggest an influence of residual confounding, careful consideration of the benefits and risk of mesh surgery for women with SUI or POP on an individual basis is required.

Keywords: urinary incontinence, epidemiology, mental health, sexual dysfunction, pain management

\section{Plain Language Summary}

Urinary incontinence (UI) is the unintended leakage of urine during normal everyday activities. It affects one in three adult women, but, despite the wide-ranging impact, fewer than $20 \%$ are actively treated. While lifestyle and drug treatments are offered in primary care in the UK, surgical care is recommended if symptoms persist. Mesh implants have been used for over 20 years to treat UI and pelvic organ prolapse (POP) (when one or more of the 
organs in the pelvis (womb/uterus, bladder or top of the vagina) slip down from their normal position and bulge into the vagina). There have been concerns about complications after mesh procedures, such as infection, pain, depression, anxiety, and a loss of sex life.

Previous studies have described harms treated in the hospital setting. Our study uses data from General Practitioners (GP) and hospital records to describe complications in patients with $\mathrm{UI}$ and POP, in the primary care setting, where patients are treated and managed by their GP long after surgery. We describe complications in those who have and have not had surgical mesh implants. Mesh surgery was associated with poor mental and sexual health outcomes, and increased medication use for pain and infection, in women with no history of these outcomes. Mesh surgery was associated with improved mental health, and lower use of pain medication, in women with a previous history of these outcomes. Despite carefully designing our study to minimise differences between women who do and do not have mesh surgery, these differences may explain some of the associations seen in our study. Our results suggest that careful consideration of the benefits and risks of mesh surgery on an individual basis is required.

\section{Introduction}

Surgical mesh has been used in urogynaecological procedures to treat stress urinary incontinence (SUI) and pelvic organ prolapse (POP) for the past 20 years. There have been concerns, however, about high rates of complications and harms. Complications may include pain, infection, depression, anxiety, sexual dysfunction, mesh erosion and further surgery. ${ }^{1-5}$ More than 100,000 women are suing manufacturers globally due to the accumulating reports of harms attributed to mesh. ${ }^{6-8}$ Pressures from patient advocacy groups alongside media exposure of harms and of failings in market approvals of mesh devices led the UK government to suspend transvaginal mesh devices in July 2018. ${ }^{9}$ However, recommendations differ between national bodies, and evidence is still lacking on the longterm health outcomes for patients who receive surgical mesh devices. ${ }^{10}$

Previous research in the UK has used Hospital Episodes Statistics (HES) data to describe complications (mainly rates of reoperation) related to mesh surgery in the hospital setting. ${ }^{5,11}$ There is a lack of evidence on longterm outcomes arising from mesh devices beyond readmission. ${ }^{1}$ Therefore, this study will use the Clinical Practice Research Datalink (CPRD) linked to HES data to examine long-term patient outcomes affecting comorbidity and quality of life, including depression, anxiety and self- harm, and sexual dysfunction, and numbers of prescriptions for antibiotics and opioid pain relief, in patients with SUI and/or POP, both with and without surgical mesh implants.

\section{Methods}

\section{Study Design}

We conducted an open cohort study of women aged 18 years and over, registered at practices contributing to the CPRD Gold database from April 01 2006. Women were eligible for inclusion if they had a diagnostic code for SUI or POP recorded in their primary care electronic medical record, and they met the following criteria: they were registered at an "up-to-standard" practice, their record was deemed "acceptable" for research based on CPRD defined quality indicators, ${ }^{12}$ and they were eligible for data linkage. Women entered the study on the latest of the study start date (April 01 2006) or the date they met all eligibility criteria. The end of the follow-up was the earliest of date of death, date of deregistration with the practice or the last date of available primary care and linked data (November 30 2018). CPRD data were linked to HES inpatient data, Office for National Statistics (ONS) mortality data and Index of Multiple Deprivation (IMD) socioeconomic status data.

\section{Exposures, Outcomes, and Covariates}

The primary exposure was a record of mesh surgery in HES inpatient or CPRD data, compared to those without mesh surgery codes (including non-mesh surgery). Women who start out in the unexposed (no mesh surgery group) can later enter the exposed group if they have mesh insertion surgery during follow-up; their contribution to the unexposed group was censored the day before the date of insertion. For the exposed group: women who had surgery before study entry were considered exposed from the point of entry; women who had surgery during follow-up entered the study, in the exposed group, at the date of insertion; where relevant, follow-up was censored at the date of mesh removal. Both groups were considered at risk of the outcome from the point of study entry. Codes for mesh surgery for SUI (tension-free vaginal tape and transobturator tapes) were introduced in April 2006. ${ }^{1}$ Sensitivity analyses excluded women with mesh surgery prior to study entry.

Outcomes considered were new episodes of depression, anxiety or self-harm (composite measure), new 
episodes of sexual dysfunction, and the number of prescriptions for antibiotics and opioids. Due to concerns of residual confounding by indication, asthma consultation rates were included as a negative control outcome: an outcome that shares the same potential sources of bias as the primary outcome but is not plausibly related to the treatment of interest (mesh surgery). All outcomes were identified from coded diagnoses and/or prescriptions in the primary care record (eTable 1 in supplement).

Covariates, measured at index date, included in the analysis were age, body mass index (BMI), ethnicity, deprivation (quintile of IMD) and general practice region.

\section{Statistical Analysis}

All analyses were conducted using Stata, version 14 (StataCorp). Data for women with SUI and POP were analysed separately. Baseline summary statistics (means and standard deviations or numbers and proportions) were calculated for the covariates and summarised by diagnosis and surgery status. The crude rate of each outcome per 100-person years of follow-up was calculated for each calendar year and presented graphically.

Cox proportional hazards models were used to examine the relationship between mesh surgery and time to new diagnoses of depression, anxiety or self-harm, adjusting for covariates and the history of the outcome prior to study entry. Equivalent analyses were carried out for sexual dysfunction. Negative binomial regression modelling was used to examine associations between rates of antibiotic prescriptions and mesh-surgery exposure, adjusting for covariates and previous use. Equivalent analyses were carried out for opioid prescriptions, and for the negative control outcome, asthma consultations.

In exploratory subgroup analyses, interaction terms between exposure and previous history of each outcome were fitted, and where there was evidence of an interaction, models were fitted stratifying according to the previous history of each outcome instead of adjusting for this variable. Post hoc analyses estimated the numbers needed to treat $(\mathrm{NNT})$ and numbers needed to harm $(\mathrm{NNH})$ for outcomes associated with mesh surgery from event rates in each group at 5 and 10 years. $^{13,14}$ Prescriptions were analysed using a time-to-first prescription model. ${ }^{15}$

\section{Missing Data}

For diagnoses and prescriptions, the absence of relevant codes was assumed to reflect the absence of disease and treatment, respectively. Data on age and practice region were complete. A missing indicator was included in models where ethnic group data was missing. Multiple imputation was used for missing BMI data: 40 imputed datasets were created by log-transforming BMI and including all covariates, exposures, and outcomes in the imputation model. The final model estimates were derived using Rubin's rules. ${ }^{16}$

\section{Ethical Approval}

The protocol for this research was approved by the Independent Scientific Advisory Committee (ISAC) of the Medicines and Healthcare Products Regulatory Agency (protocol number 19_167), and the approved protocol is available on request. Ethical approval for observational research using the CPRD with approval from ISAC has been granted by the National Research Ethics Service Committee (Trent Multi Research Ethics Committee, REC reference number 05/MRE04/87).

\section{Results}

In total, 220,544 women, from 400 practices, were included in the cohort: $74 \%(\mathrm{n}=162,687)$ with SUI and $37 \%(n=82,123)$ with POP, of which $11 \%(n=24,266)$ had codes for both SUI and POP (eFigure 1). For SUI, there were 657,169 person-years of eligible follow-up, and for POP, there were 391,481 person-years of follow-up. The median length of follow-up was 2.7 years (IQR: 0.66.7 years) for SUI and 4.1 years (IQR: 4.2-7.9) for POP, with a maximum of 12.7 years follow-up in both groups.

Table 1 shows baseline characteristics for the included participants by diagnosis of SUI and POP. More women had mesh surgery after study entry for SUI than for POP (6475 [3.9\%] vs 2108 [2.5\%]). Women with SUI were slightly younger than those with POP (58.9 vs 64.5 years). There was a higher prevalence of previous depression, anxiety and self-harm (37.4\% vs $28.6 \%)$, and a lower proportion had mesh surgery prior to study entry $(18.9 \%$ vs $40.7 \%$ ). Other characteristics were similar. Table 2 shows the characteristics of women who had received a mesh device by diagnosis. BMI, and deprivation were similar in those with and without a mesh device. Age was similar in women with POP with and without a mesh device, but women with mesh surgery for SUI were slightly younger. Proportions receiving surgery were slightly higher in white women and slightly lower in all other ethnic groups. Mesh operations were largely carried out after April 01 2006, for SUI, as we would expect with the introduction of specific codes for tension-free vaginal 
Table I Baseline Characteristics of 162,687 Women with Stress Urinary Incontinence and 82,123 Women with Pelvic Organ Prolapse. Data are Mean \pm SD or \% (N)

\begin{tabular}{|c|c|c|}
\hline Variable & $\begin{array}{l}\text { Stress Urinary } \\
\text { Incontinence }\end{array}$ & $\begin{array}{l}\text { Pelvic Organ } \\
\text { Prolapse }\end{array}$ \\
\hline $\mathrm{N}^{\mathrm{a}}$ & $\begin{array}{l}\text { 162,687 women } \\
\text { (5185 of whom are } \\
\text { eligible as unexposed } \\
\text { and exposed) }\end{array}$ & $\begin{array}{l}82,123 \text { women ( } 1185 \\
\text { of whom are eligible in } \\
\text { both unexposed and } \\
\text { exposed) }\end{array}$ \\
\hline Age (years) & $58.9 \pm 18.8$ & $64.2 \pm 15.0$ \\
\hline $\begin{array}{l}\text { Body mass index } \\
(\mathrm{kg} / \mathrm{m} 2)(\mathrm{N}: \mathrm{SUl}= \\
57,055 ; \\
\mathrm{POP}=24,603)\end{array}$ & $27.7 \pm 6.7$ & $27.1 \pm 5.4$ \\
\hline \multicolumn{3}{|c|}{ IMD Quintile (N missing: SUI I09; POP 62) } \\
\hline $\begin{array}{l}\text { I (least } \\
\text { deprived) }\end{array}$ & $38,853(23.2)$ & $21,757(26.1)$ \\
\hline 2 & $38,207(22.8)$ & $21,146(25.4)$ \\
\hline 3 & $34,105(20.3)$ & $16,921(20.3)$ \\
\hline 4 & $31,057(18.5)$ & $13,889(16.7)$ \\
\hline $\begin{array}{l}5 \text { (most } \\
\text { deprived) }\end{array}$ & $25,539(15.2)$ & $9533(11.5)$ \\
\hline \multicolumn{3}{|l|}{ Ethnicity } \\
\hline White & 149,687 (89.2) & $76,490(91.8)$ \\
\hline South Asian & $4646(2.8)$ & $1403(1.7)$ \\
\hline Black & $2430(1.4)$ & $693(0.8)$ \\
\hline Other/Mixed & $1860(1.1)$ & $579(0.7)$ \\
\hline $\begin{array}{l}\text { Not stated/ } \\
\text { missing }\end{array}$ & $9249(5.5)$ & $4 \mid 43(5.0)$ \\
\hline \multicolumn{3}{|l|}{ Region } \\
\hline North East & $3502(2.1)$ & $1679(2.0)$ \\
\hline North West & $25,853(15.4)$ & $|2,20|(\mid 4.6)$ \\
\hline $\begin{array}{l}\text { Yorkshire \& The } \\
\text { Humber }\end{array}$ & $6702(4.0)$ & $3468(4.2)$ \\
\hline East Midlands & $4360(2.6)$ & $2391(2.9)$ \\
\hline West Midlands & $20,389(12.1)$ & $10,269(12.3)$ \\
\hline East of England & I9,55| (II.6) & $9696(11.6)$ \\
\hline South West & $22,650(13.5)$ & II,I48 (I3.4) \\
\hline South Central & $21,957(13.1)$ & II,742 (I4.I) \\
\hline London & $21,260(12.7)$ & $9162(11.0)$ \\
\hline
\end{tabular}

(Continued)
Table I (Continued).

\begin{tabular}{|l|l|l|}
\hline Variable & $\begin{array}{l}\text { Stress Urinary } \\
\text { Incontinence }\end{array}$ & $\begin{array}{l}\text { Pelvic Organ } \\
\text { Prolapse }\end{array}$ \\
\hline $\begin{array}{c}\text { South East } \\
\text { Coast }\end{array}$ & $21,648(12.9)$ & $11,552(13.9)$ \\
\hline $\begin{array}{l}\text { Previous } \\
\text { depression, anxiety } \\
\text { or self-harm } \\
\text { record }\end{array}$ & $62,766(37.4)$ & $23,844(28.6)$ \\
\hline $\begin{array}{l}\text { Previous sexual } \\
\text { dysfunction record }\end{array}$ & $4907(2.9)$ & $1992(2.4)$ \\
\hline $\begin{array}{l}\text { Previous antibiotic } \\
\text { prescription }\end{array}$ & $151,076(90.0)$ & $73,329(88.0)$ \\
\hline $\begin{array}{l}\text { Previous opioid } \\
\text { prescription }\end{array}$ & $99,933(59.5)$ & $48,532(58.3)$ \\
\hline Mesh surgery & $6475(4.0)$ & $859(40.7)$ \\
\hline $\begin{array}{l}\text { Mesh surgery } \\
\text { before study entry }\end{array}$ & $1224(18.9)$ & $(2.6)$ \\
\hline
\end{tabular}

Notes: ${ }^{a}$ Women can appear in both SUI and POP groups. SUl: 162,687 women, 5185 of whom are eligible as unexposed and exposed. POP: 82, 123 women, 1185 of whom are eligible in both unexposed and exposed.

tape and transobturator tapes in April 2006. ${ }^{1}$ Operations for POP occurred prior to 2000 through to the end of follow-up. There was a higher prevalence of depression, anxiety and self-harm and sexual dysfunction in women with mesh surgery for SUI and POP (SUI: 62.4 vs 36.4\%; POP: 40.7 vs $28.3 \%$ ). The prevalence of previous antibiotic and opioid prescriptions was similar in women with and without mesh surgery for SUI and POP.

\section{Stress Urinary Incontinence}

Unadjusted rates of depression, anxiety, and self-harm were higher in women who had mesh surgery (Figure 1A; Table 3: unadjusted HR 1.60, 95\% CI 1.54 to 1.66). After adjustment, the association was reversed (adjusted HR $0.78,95 \%$ CI 0.78 to 0.81 ). Subgroup analyses showed that in women with no previous history of depression, anxiety or self-harm, the risk of an episode was greater with mesh surgery (adjusted HR 2.43 (95\% CI 2.19 to 2.70$)$ ). In women who had a previous history, the risk of further episodes of depression, anxiety or self-harm was lower in women who had mesh surgery, even after adjustment for covariates (adjusted HR $0.70,95 \%$ CI 0.67 to 0.73$)$. 
Table 2 Baseline Characteristics of 162,687 Women with Stress Urinary Incontinence and 82, I23 Women with Pelvic Organ Prolapse by Mesh Surgery Status. Data are Mean \pm SD or \% (N)

\begin{tabular}{|c|c|c|c|c|}
\hline \multirow[b]{2}{*}{ Variable } & \multicolumn{2}{|c|}{ Stress Urinary Incontinence } & \multicolumn{2}{|c|}{ Pelvic Organ Prolapse } \\
\hline & No Mesh Surgery & Mesh Surgery & No Mesh Surgery & Mesh Surgery \\
\hline $\mathrm{N}^{\mathrm{a}}$ & 161,397 & 6475 & 81,200 & 2108 \\
\hline Age (years) & $59.1 \pm 19.0$ & $54.4 \pm 12.5$ & $64.2 \pm 15.0$ & $63.9 \pm 11.8$ \\
\hline Body mass index $(\mathrm{kg} / \mathrm{m} 2)(\mathrm{N}: \mathrm{SUl}=57,055 ; \mathrm{POP}=24,603)$ & $27.7 \pm 6.7$ & $28.4 \pm 6.0$ & $27.1 \pm 5.4$ & $26.9 \pm 4.7$ \\
\hline \multicolumn{5}{|l|}{ IMD Quintile (N missing: SUI 109; POP 62) } \\
\hline I (least deprived) & $37,368(23.2)$ & $1485(22.9)$ & $21,216(26.1)$ & $54 \mid(25.7)$ \\
\hline 2 & $36,664(22.7)$ & $1543(23.8)$ & $20,596(25.4)$ & $550(26.1)$ \\
\hline 3 & $32,737(20.3)$ & $1368(2 \mid .1)$ & $16,496(20.3)$ & $425(20.2)$ \\
\hline 4 & $29,822(18.5)$ & $1235(19.1)$ & $13,530(16.7)$ & $359(17.0)$ \\
\hline 5 (most deprived) & $24,699(15.3)$ & $840(13.0)$ & 9301 (II.5) & $232(11.0)$ \\
\hline \multicolumn{5}{|l|}{ Ethnicity } \\
\hline White & $143,502(88.9)$ & $6185(95.5)$ & 74,452 (91.7) & $2038(96.7)$ \\
\hline South Asian & $4558(2.8)$ & $88(1.4)$ & $1384(1.7)$ & $19(0.9)$ \\
\hline Black & $2393(1.5)$ & $37(0.6)$ & $677(0.8)$ & $16(0.8)$ \\
\hline Other/Mixed & $1810(1.1)$ & $50(0.8)$ & $570(0.7)$ & $9(0.4)$ \\
\hline Not stated & $9134(5.7)$ & $115(1.8)$ & $4117(5.1)$ & $26(1.2)$ \\
\hline \multicolumn{5}{|l|}{ Region } \\
\hline North East & $3391(2.1)$ & III (I.7) & $1656(2.0)$ & $23(1.1)$ \\
\hline North West & $24,965(15.5)$ & $888(13.7)$ & $11,914(14.7)$ & $287(13.6)$ \\
\hline Yorkshire \& The Humber & $6496(4.0)$ & $206(3.2)$ & $3404(4.2)$ & $64(3.0)$ \\
\hline East Midlands & $4230(2.6)$ & $130(2.0)$ & $2329(2.9)$ & $62(2.9)$ \\
\hline West Midlands & $19,687(12.2)$ & $702(10.8)$ & $10,034(12.4)$ & $235($ (II.I) \\
\hline East of England & I8,859 (II.7) & $692(10.7)$ & $9403($ (II.6) & $293(13.9)$ \\
\hline South West & $21,783(13.5)$ & $867(13.4)$ & $10,758(13.2)$ & $390(18.5)$ \\
\hline South Central & $20,919(13.0)$ & $1038(16.0)$ & II,473 (I4.I) & $269(12.8)$ \\
\hline London & $20,564(12.7)$ & $696(10.7)$ & $8976($ (II.I) & $186(8.8)$ \\
\hline South East Coast & $20,503(12.7)$ & $1145(17.7)$ & II,253 (13.9) & $299(14.2)$ \\
\hline Previous depression, anxiety or self-harm record & $58,728(36.4)$ & $4038(62.4)$ & $22,985(28.3)$ & $859(40.7)$ \\
\hline Previous sexual dysfunction record & $4499(2.8)$ & $408(6.3)$ & $1916(2.4)$ & $76(3.6)$ \\
\hline Previous antibiotic prescription & $145, \mid 14(89.9)$ & $5962(92.1)$ & 7I,436 (88.0) & $1893(89.8)$ \\
\hline Previous opioid prescription & $95,935(59.4)$ & $3998(61.7)$ & $47,175(58.1)$ & $1357(64.4)$ \\
\hline Incident depression, anxiety or self-harm record & $4 I, 355(25.6)$ & $2828(43.7)$ & $15,313(18.9)$ & $535(25.4)$ \\
\hline Incident sexual dysfunction record & $1170(0.7)$ & $108(1.7)$ & $520(0.6)$ & $20(0.9)$ \\
\hline
\end{tabular}


Table 2 (Continued).

\begin{tabular}{|c|c|c|c|c|}
\hline \multirow[b]{2}{*}{ Incident antibiotic prescription } & \multicolumn{2}{|c|}{ Stress Urinary Incontinence } & \multicolumn{2}{|c|}{ Pelvic Organ Prolapse } \\
\hline & $124,203(77.0)$ & $5120(79.1)$ & $62,602(77.1)$ & $1636(77.6)$ \\
\hline Incident opioid prescription & $75,959(47.1)$ & $2933(45.3)$ & $38,951(48.0)$ & $1047(49.7)$ \\
\hline Mesh surgery before entry & & $1224(18.9)$ & & $859(40.7)$ \\
\hline \multicolumn{5}{|l|}{ Surgical speciality } \\
\hline Gynaecology & & $5119(79.1)$ & & $1814(86.1)$ \\
\hline Obstetric & & $637(9.8)$ & & $214(10.2)$ \\
\hline Urology & & $704(10.9)$ & & $10(0.5)$ \\
\hline Other & & $15(0.2)$ & & $70(3.3)$ \\
\hline \multicolumn{5}{|l|}{ Year of mesh surgery } \\
\hline Before $1 / 4 / 2006^{\mathrm{b}}$ & & $15 \mid(2.3)$ & & $638(32.0)$ \\
\hline I/4/2006-2009 & & $2786(43.0)$ & & $507(25.5)$ \\
\hline $2010-2014$ & & $2986(46.1)$ & & $688(34.5)$ \\
\hline$\geq 2015$ & & $552(8.5)$ & & $159(8.0)$ \\
\hline
\end{tabular}

Notes: ${ }^{a}$ Women can appear in both surgery groups: women were in the unexposed group up until the date of mesh surgery, at which point they joined the exposed group and were followed until the end-of-follow up or date of mesh removal. Women who had mesh surgery before study entry were considered exposed from the point of study entry. SUI: 162,687 women, 5185 of whom are eligible as unexposed and exposed. POP: 82,123 women, 1185 of whom are eligible in both unexposed and exposed.

${ }^{\mathrm{b}}$ April $0 \mathrm{I} 2006$ is the study start date as specific codes for SUI mesh only introduced on this date.

Rates of sexual dysfunction were higher in women with SUI who had mesh surgery compared with those who had not (Figure 1B; Table 3: unadjusted HR 1.88, 95\% CI 1.55 to 2.29 ; adjusted HR $1.55,95 \%$ CI 1.27 to 1.90). Subgroup analyses showed an increased risk of sexual dysfunction in women who had mesh surgery in women who had no previous history of sexual dysfunction, adjusted HR 1.88 (95\% CI 1.50 to 2.36); there was no evidence of an association in those with a previous history of the outcome, but estimates were imprecise (adjusted HR $0.86(95 \%$ CI $0.55,1.35))$.

Rates of antibiotic prescriptions were higher in women who had mesh surgery (Figure 1C; Table 3: unadjusted IRR 1.15, 95\% CI 1.12 to 1.18 ; adjusted IRR $1.15,95 \%$ CI 1.13 to 1.18 ). There was an increased rate of antibiotic prescriptions in women who had mesh surgery, in both women with and without a previous history of antibiotic prescriptions; the rate appeared to be higher in women with no previous history (Table 3, adjusted IRR: women with no history 1.47 (95\% CI 1.30 to 1.66 ), and women with previous history 1.17 (95\% CI 1.14 to 1.20$)$ ).

There was no clear trend over time in the rate of opioid prescriptions in women who did and did not have mesh surgery (Figure 1D). In multivariate analyses a decreased rate of opioid prescription was seen in women who had mesh surgery (Table 3). Subgroup analyses showed that, in women with no previous history of an opioid prescription, there was an increased rate of a new prescription in those who had mesh surgery, adjusted IRR 1.40 (95\% CI 1.26 to 1.56); there was no evidence of an association in women with prior prescriptions of opioids, adjusted IRR 1.02 (95\% CI 0.99 to 1.05 ).

\section{Pelvic Organ Prolapse}

Unadjusted rates of depression, anxiety, and self-harm were higher in women who had mesh surgery (Figure 1E; Table 3: unadjusted HR 1.28, 95\% CI 1.17 to 1.39). After adjustment, there was a lower risk of depression, anxiety and self-harm in those with mesh surgery (adjusted HR 0.77, 95\% CI 0.70 to 0.84 ). Subgroup analyses showed that women without a previous history of depression, anxiety or self-harm had a greater risk of these outcomes after mesh-surgery, adjusted HR 1.47 (95\% CI 1.19 to 1.81), and women with a history of these outcomes had a lower risk after mesh surgery (adjusted HR 0.72 (95\% CI 0.65 to 0.79$)$ ). 
A Rate of depression, anxiety or self-harm

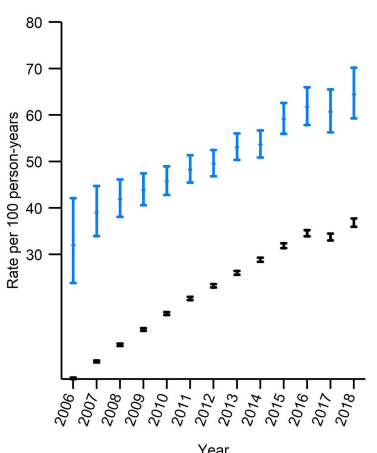

$E_{1}$

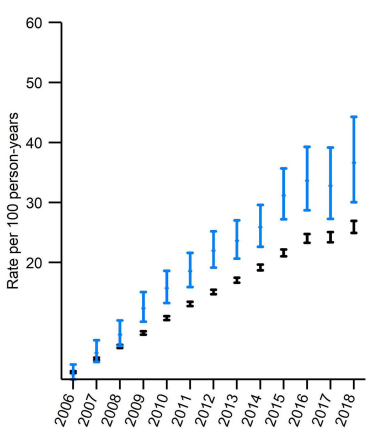

Year

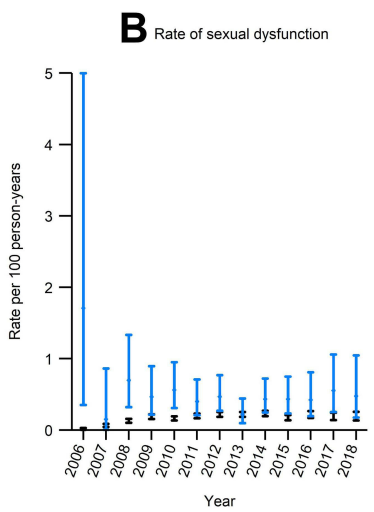

$F_{\text {Rate of sexual dystunction }}$

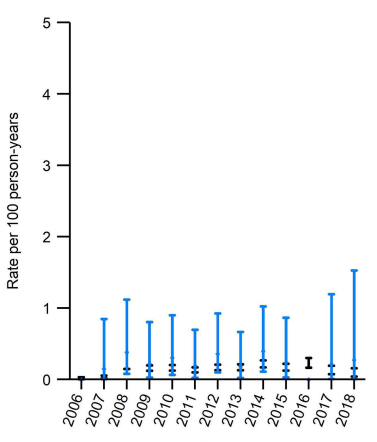

Year

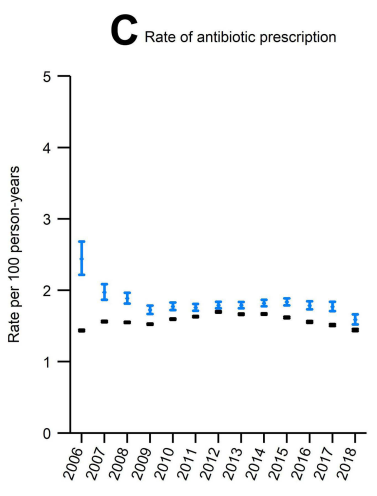

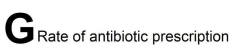

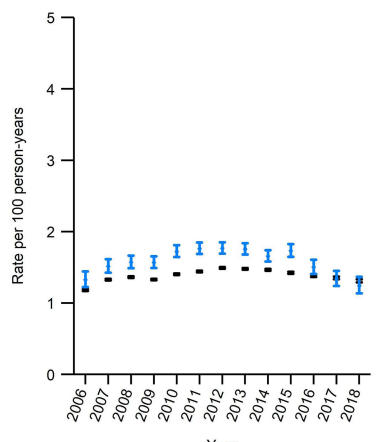

Year

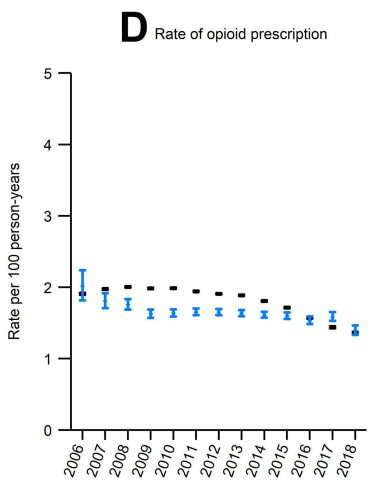

$H_{\text {Rate of oppiod prescripition }}$

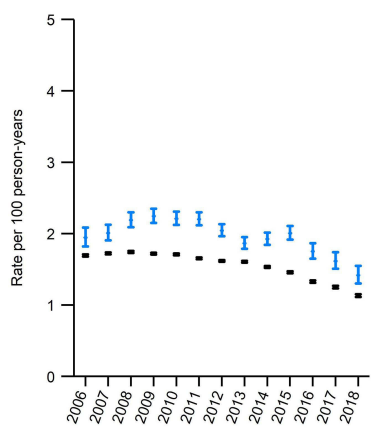

Year

Figure I Annual rates and 95\% confidence intervals of each outcome in 162,687 women with stress urinary incontinence (A-D) and 82, I23 women with pelvic organ prolapse (E-H), in women with mesh surgery and no surgery.

Notes: Black - No mesh surgery; Blue - Mesh surgery. No surgery; $\bullet$ Mesh surgery.

There was no evidence of an association between rates of sexual dysfunction and mesh surgery (Figure 1F; Table 3), although event numbers are small, and estimates are imprecise with wide confidence intervals. Confidence intervals suggest the effect could be as small as 0.76 or as high as 1.87. Subgroup analyses suggest that women with no previous history of sexual dysfunction had a greater risk of these outcomes after mesh-surgery, although estimates were imprecise, adjusted HR 1.64 (95\% CI 1.02 to 2.64). In women with a previous history of these outcomes, there was no evidence that the risk of a further episode was associated with mesh surgery (HR 0.32 (95\% CI 0.08, 1.31)). Confidence intervals suggest that the effect could be as low as 0.08 and as high as 1.31, suggesting a large degree of imprecision.

Rates of antibiotic prescriptions were higher in women who had mesh surgery (Figure 1G, Table 3: unadjusted IRR $1.13,95 \%$ CI 1.08 to 1.19 ; adjusted IRR 1.09 , 95\% CI 1.04 to 1.14 ). There is no evidence of an interaction, so subgroup analyses are not presented.

Unadjusted rates of opioids were higher in women with mesh surgery (Figure 1H). After adjustment, the rates of opioid prescriptions were reduced in women who had mesh surgery (IRR $0.79,95 \%$ CI 0.74 to 0.84 ). Subgroup analyses suggest that women with no previous history of opioid prescriptions, have an increased rate of new opioid prescriptions, adjusted IRR 1.23 (95\% CI 1.01 to 1.49), although confidence intervals suggest the effect could be as small as 1.01. In women with a previous prescription, rates of further prescriptions were lower, adjusted IRR 0.91 (95\% CI 0.86 to 0.96 ).

Table 4 presents NNT and NNH for each outcome at 5 and 10 years; positive numbers should be interpreted as NNT, and negative numbers should be interpreted as NNH. For example, at 5 years, overall, for every 10.6 (95\% CI 10.6 to 10.7 ) women with no previous history of depression, anxiety and self-harm, who undergo SUI mesh surgery, there is one additional episode of depression, anxiety and self-harm. Whereas in women with a previous history of depression, anxiety and self-harm, at 5 years, for every 18 women (95\% CI 17.6 to 18.3 ) who undergo SUI mesh surgery, there is one fewer episode of depression, anxiety and self-harm. There is no evidence of an interaction between a previous history of antibiotic or opioid prescriptions and mesh exposure, thus these analyses and NNH are presented for all women. 
Table 3 Unadjusted and Adjusted ${ }^{a}$ Hazard Ratios/Incidence Rate Ratios for Outcomes, Comparing Mesh Surgery with No Surgery, in 162,578 Women with Stress Urinary Incontinence and 82,06I Women with Pelvic Organ Prolapse

\begin{tabular}{|c|c|c|c|c|c|c|c|c|c|c|c|c|}
\hline \multirow{3}{*}{$\begin{array}{l}\text { Ratios are for Mesh } \\
\text { Surgery, Reference } \\
\text { Group of No Mesh } \\
\text { Surgery }\end{array}$} & \multicolumn{12}{|c|}{ Outcome } \\
\hline & \multicolumn{3}{|c|}{ Depression, Anxiety and Self-Harm } & \multicolumn{3}{|c|}{ Sexual Dysfunction } & \multicolumn{3}{|c|}{ Antibiotic Prescriptions } & \multicolumn{3}{|c|}{ Opioid Prescriptions } \\
\hline & $\begin{array}{l}\text { Number of } \\
\text { Observations }\end{array}$ & $\begin{array}{l}\text { Unadjusted } \\
\text { HR }(95 \% \\
\mathrm{Cl})\end{array}$ & $\begin{array}{l}\text { Adjusted } \\
{ }^{\mathrm{a}} \mathrm{HR} \\
(95 \% \mathrm{Cl})\end{array}$ & $\begin{array}{l}\text { Number of } \\
\text { Observations }\end{array}$ & $\begin{array}{l}\text { Unadjusted } \\
\text { HR }(95 \% \\
\mathrm{Cl})\end{array}$ & $\begin{array}{l}\text { Adjusted } \\
{ }^{a} \mathrm{HR} \\
(95 \% \mathrm{Cl})\end{array}$ & $\begin{array}{l}\text { Number of } \\
\text { Observations }\end{array}$ & $\begin{array}{l}\text { Unadjusted } \\
\text { IRR (95\% } \\
\text { Cl) }\end{array}$ & $\begin{array}{l}\text { Adjusted } \\
{ }^{a} \text { IRR } \\
(95 \% \mathrm{CI})\end{array}$ & $\begin{array}{l}\text { Number of } \\
\text { Observations }\end{array}$ & $\begin{array}{l}\text { Unadjusted } \\
\text { IRR ( } 95 \% \\
\text { Cl) }\end{array}$ & $\begin{array}{l}\text { Adjusted } \\
{ }^{\text {a }} \text { IRR } \\
(95 \% \mathrm{CI})\end{array}$ \\
\hline \multicolumn{13}{|c|}{ Stress urinary incontinence } \\
\hline All women & $|67,76|$ & $\begin{array}{l}1.60 \\
(1.54,1.66)\end{array}$ & $\begin{array}{l}0.78 \\
(0.75,0.81)\end{array}$ & $|67,76|$ & $\begin{array}{l}1.88 \\
(1.55,2.29)\end{array}$ & $\begin{array}{l}1.55 \\
(1.27,1.90)\end{array}$ & $|67,76|$ & $\begin{array}{l}1.15 \\
(1.12,1.18)\end{array}$ & $\begin{array}{l}1.15 \\
(1.13,1.18)\end{array}$ & $|67,76|$ & $\begin{array}{l}1.20 \\
(1.17,1.23)\end{array}$ & $\begin{array}{l}0.93 \\
(0.90,0.96)\end{array}$ \\
\hline $\begin{array}{l}\text { No previous history of } \\
\text { the outcome }\end{array}$ & 105,036 & $\begin{array}{l}2.18 \\
(1.97,2.42)\end{array}$ & $\begin{array}{l}2.43 \\
(2.19,2.70)\end{array}$ & 162,855 & $\begin{array}{l}1.93 \\
(1.55,2.41)\end{array}$ & $\begin{array}{l}1.88 \\
(1.50,2.36)\end{array}$ & 16,785 & $\begin{array}{l}1.37 \\
(1.21,1.55)\end{array}$ & $\begin{array}{l}1.47 \\
(1.30,1.66)\end{array}$ & 67,896 & $\begin{array}{l}1.29 \\
(1.16,1.44)\end{array}$ & $\begin{array}{l}1.40 \\
(1.26,1.56)\end{array}$ \\
\hline $\begin{array}{l}\text { Previous history of the } \\
\text { outcome }\end{array}$ & 62,725 & $\begin{array}{l}0.70 \\
(0.67,0.73)\end{array}$ & $\begin{array}{l}0.70 \\
(0.67,0.73)\end{array}$ & 4906 & $\begin{array}{l}0.74 \\
(0.48,1.15)\end{array}$ & $\begin{array}{l}0.86 \\
(0.55,1.35)\end{array}$ & 150,976 & $\begin{array}{l}1.14 \\
(1.11,1.17)\end{array}$ & $\begin{array}{l}1.17 \\
(1.14,1.20)\end{array}$ & 99,865 & $\begin{array}{l}1.15 \\
(1.12,1.18)\end{array}$ & $\begin{array}{l}1.02 \\
(0.99,1.05)\end{array}$ \\
\hline \multicolumn{13}{|l|}{ Pelvic organ prolapse } \\
\hline All women & 83,246 & $\begin{array}{l}1.28 \\
(1.17,1.39)\end{array}$ & $\begin{array}{l}0.77 \\
(0.70,0.84)\end{array}$ & 83,246 & $\begin{array}{l}1.33 \\
(0.85,2.07)\end{array}$ & $\begin{array}{l}1.19 \\
(0.76,1.87)\end{array}$ & 83,246 & $\begin{array}{l}1.13 \\
(1.08,1.19)\end{array}$ & $\begin{array}{l}1.09 \\
(1.04,1.14)\end{array}$ & 83,246 & $\begin{array}{l}1.03 \\
(0.98,1.08)\end{array}$ & $\begin{array}{l}0.79 \\
(0.74,0.84)\end{array}$ \\
\hline $\begin{array}{l}\text { No previous history of } \\
\text { the outcome }\end{array}$ & 59,416 & $\begin{array}{l}1.39 \\
(1.12,1.71)\end{array}$ & $\begin{array}{l}1.47 \\
(1.19,1.81)\end{array}$ & 81,255 & $\begin{array}{l}1.52 \\
(0.95,2.44)\end{array}$ & $\begin{array}{l}1.64 \\
(1.02,2.63)\end{array}$ & & & & 34,757 & $\begin{array}{l}1.27 \\
(1.05,1.55)\end{array}$ & $\begin{array}{l}1.23 \\
(1.01,1.49)\end{array}$ \\
\hline $\begin{array}{l}\text { Previous history of the } \\
\text { outcome }\end{array}$ & 23,830 & $\begin{array}{l}0.70 \\
(0.64,0.77)\end{array}$ & $\begin{array}{l}0.72 \\
(0.65,0.79)\end{array}$ & 1991 & $\begin{array}{l}0.34 \\
(0.08,1.36)\end{array}$ & $\begin{array}{l}0.32 \\
(0.08,1.31)\end{array}$ & & & & 48,489 & $\begin{array}{l}1.01 \\
(0.96,1.05)\end{array}$ & $\begin{array}{l}0.91 \\
(0.86,0.96)\end{array}$ \\
\hline
\end{tabular}

Notes: a'Rows for all women were adjusted for age (5 year groups), body mass index (<18.5, 18.5-24.9, 25-29.9, $\geq 30 \mathrm{~kg} / \mathrm{m} 2)$, deprivation quintiles, ethnicity (“white”, “Asian”, "black”, “other”/“mixed”, missing), Strategic Health Authority region, history of the outcome. Rows stratified by previous history of the outcome are adjusted for all the above variables except for previous history of the outcome. 
Table 4 Numbers Needed to Treat/Harm a and Estimated 95\% Confidence at 5 and 10 Years Follow-Up, for Each Outcome, for 162,578 Women with Stress Urinary Incontinence and 82,061 Women with Pelvic Organ Prolapse and Stratified by a Previous History of the Outcome ${ }^{\text {b }}$

\begin{tabular}{|c|c|c|c|c|c|c|c|c|}
\hline & \multicolumn{2}{|c|}{$\begin{array}{l}\text { Depression, Anxiety and Self- } \\
\text { Harm }\end{array}$} & \multicolumn{2}{|c|}{ Sexual Dysfunction } & \multicolumn{2}{|c|}{ Antibiotic Prescriptions } & \multicolumn{2}{|c|}{ Opioid Prescriptions } \\
\hline & NNT 5 Years $^{a}$ & NNT 10 Years $^{a}$ & NNT 5 Years $^{a}$ & NNT 10 Years $^{a}$ & NNT 5 Years $^{a}$ & NNT 10 Years $^{a}$ & NNT 5 Years $^{a}$ & NNT 10 Years $^{a}$ \\
\hline \multicolumn{9}{|l|}{ Stress urinary incontinence } \\
\hline All women ${ }^{b}$ & $\begin{array}{l}23.1 \\
(22.8,23.3)\end{array}$ & $\begin{array}{l}22.9 \\
(22.7,23.1)\end{array}$ & $\begin{array}{l}-206.9 \\
(-271.4,-142.4)\end{array}$ & $\begin{array}{l}-143.1 \\
(-186.8,-99.4)\end{array}$ & $\begin{array}{l}-21.3 \\
(-21.4,-21.1)\end{array}$ & $\begin{array}{l}-42.9 \\
(-43.3,-42.6)\end{array}$ & $\begin{array}{l}-276.0 \\
(-376.9,-175.1)\end{array}$ & $\begin{array}{l}-292.4 \\
(-399.1,-185.6)\end{array}$ \\
\hline No previous history of the outcome ${ }^{b}$ & $\begin{array}{l}-10.6 \\
(-10.7,-10.6)\end{array}$ & $\begin{array}{l}-8.2 \\
(-8.3,-8.2)\end{array}$ & $\begin{array}{l}-159.3 \\
(-199.8,-118.8) \\
\end{array}$ & $\begin{array}{l}-110.2 \\
(-137.9,-82.5)\end{array}$ & & & & \\
\hline Previous history of the outcome ${ }^{b}$ & $\begin{array}{l}18.0 \\
(17.6,18.3)\end{array}$ & $\begin{array}{l}19.2 \\
(18.8,19.6)\end{array}$ & c & c & & & & \\
\hline \multicolumn{9}{|l|}{ Pelvic organ prolapse } \\
\hline All women ${ }^{b}$ & $\begin{array}{l}28.9 \\
(28.4,29.3)\end{array}$ & $\begin{array}{l}27.1 \\
(26.7,27.5)\end{array}$ & $\begin{array}{l}-726.1 \\
(-901.2,-550.9)\end{array}$ & $\begin{array}{l}-544.2 \\
(-674.0,-4 \mid 4.4)\end{array}$ & $\begin{array}{l}-22.4 \\
(-22.9,-22.0)\end{array}$ & $\begin{array}{l}-41.3 \\
(-42.0,-40.5)\end{array}$ & $\begin{array}{l}-42.8 \\
(-49.0,-36.6)\end{array}$ & $\begin{array}{l}-44.6 \\
(-51.0,-38.2)\end{array}$ \\
\hline No previous history of the outcome ${ }^{b}$ & $\begin{array}{l}-45.1 \\
(-46.2,-43.9)\end{array}$ & $\begin{array}{l}-32.6 \\
(-33.5,-31.8)\end{array}$ & $\begin{array}{l}-271.5 \\
(-328.3,-214.8)\end{array}$ & $\begin{array}{l}-205.7 \\
(-248.4,-163.0)\end{array}$ & & & & \\
\hline Previous history of the outcome ${ }^{b}$ & $\begin{array}{l}15.7 \\
(15.4,16.0)\end{array}$ & $\begin{array}{l}15.7 \\
(15.4,16.1)\end{array}$ & c & c & & & & \\
\hline
\end{tabular}

Notes: ${ }^{2}$ Positive numbers should be interpreted as the number needed to treat: for example, at 5 years, for every $18.0(95 \% \mathrm{Cl} 17.6$ to 18.3$)$ women with a previous history of depression, anxiety and self-harm who undergo SUI mesh surgery, there is I fewer diagnosis of depression, anxiety and self-harm. Negative numbers should be interpreted as a number needed to harm: for example, at 5 years, for every 10.6 women ( $95 \%$ Cl 10.6 to I0.7) with no previous history of depression, anxiety and self-harm who undergo SUI mesh surgery, there is I extra episode of these outcomes. "Estimated from a Cox proportional hazards model, so time to first diagnosis of depression, anxiety or self-harm, or time to first prescription of antibiotics, adjusted for age (5 year groups), body mass index (<18.5, 18.5-24.9, 25-29.9, $\geq 30 \mathrm{~kg} / \mathrm{m}^{2}$ ), deprivation quintiles, ethnicity ("white", "Asian", "black", "other"/“mixed", missing), Strategic Health Authority region, history of the outcome. Rows stratified by previous history of the outcome are adjusted for all the above variables except for previous history of the outcome. Hazard ratios and $95 \%$ confidence intervals for depression, anxiety and self-harm and sexual dysfunction are shown in Table 3 , and in eTable 2 for antibiotic and opioid prescriptions. 'Due to very small numbers in women aged $\geq 80$ years with mesh surgery ( $<5$ women), confidence intervals could not be properly estimated. 
Sensitivity analyses excluding women who underwent mesh surgery prior to study entry gave similar results (eTable 3).

The association between asthma consultations (our negative control outcome) and mesh surgery in women with SUI or with POP is presented in eTable 4. Unadjusted analyses show a higher rate of asthma consultations in women with mesh surgery for SUI compared to those with no mesh surgery (unadjusted IRR 1.34 (95\% CI 1.30 to 1.37$)$ ). After adjustment, there was a slightly lower consultation rate for asthma in women with mesh surgery for SUI (adjusted IRR 0.91 (95\% CI 0.88 to 0.95)). For women with POP, unadjusted analyses showed a higher rate of consultations for women with mesh surgery (unadjusted IRR 1.27 (95\% CI 1.19 to 1.35)), but after adjustment there was no evidence of an association, although estimates are not especially precise (adjusted IRR 1.03 (95\% CI 0.81 to 1.32$)$ ).

\section{Discussion}

In this large study of electronic health records, rates of antibiotic prescriptions were higher in women undergoing mesh surgery for SUI or POP. The NNH at 5 years suggest that there is an extra-antibiotic prescription for every 21.3 (95\% CI 21.1 to 21.4 ) women who undergo SUI mesh surgery and $22.4(95 \%$ CI 22.0 to 22.9$)$ women who undergo POP mesh surgery. Rates of depression, anxiety, self-harm, sexual dysfunction, and opioid prescriptions were higher in women with no previous history of these outcomes who had mesh surgery for SUI or POP. Of these outcomes, the lowest NNH was seen for depression, anxiety and self-harm, with one extra episode for every 10.6 (95\% CI 10.6 to 10.7$)$ women undergoing SUI mesh surgery. For POP mesh surgery, the NNH at 5 years was similar for depression, anxiety and self-harm, where there was one extra episode for every 45.1 (95\% CI 43.9 to 46.2) women and for opioid prescriptions, where there was one extra prescription for every 42.8 (95\% CI 36.6 to 49.0 ) women. A lower rate of depression, anxiety and self-harm was seen in women with a history of these outcomes who had mesh surgery for SUI or POP. The NNT at 5 years suggests that there is one fewer episode of these diagnoses for every 19.2 (95\% CI 18.8-19.6) and 15.7 (95\% CI 15.4-16.1) women undergoing SUI and POP mesh surgery, respectively. Lower rates of opioid prescriptions were seen in women with a previous history of prescriptions who had mesh surgery for POP. While there was no evidence of an association between our negative control outcome asthma consultation rates and mesh surgery in women with POP, the rate of asthma consultations in women with mesh surgery for SUI was lower than that in women with non-mesh surgery. This suggests that residual confounding may still be an issue in our study design and results should be interpreted with caution. Our results suggest that careful consideration of the benefits and risks of mesh surgery for women with SUI or POP on an individual basis is required.

\section{Comparison with the Existing Literature}

In 2017, NICE draft guidance ${ }^{17}$ recommended that the repair of POP using transvaginal mesh should not be done except in the context of research. And in July 2018, Baroness Cumberlege, chair of the Independent Medicines and Medical Devices Safety Review (IMMDS), ${ }^{1}$ called for a halt in the use of mesh for SUI until conditions affecting training, registration, and licensing were met. Based on updated NICE guidance, ${ }^{18}$ in April 2019, the mesh ban was lifted, with changes. NICE recommended that the mesh could be used once certain conditions were met. However, it is still subject to a period of "high vigilance restriction."

One of the main problems was the lack of evidence informing long-term complications in NICE's evidence review. For SUI, NICE found 141 studies and reported 109 RCTs on clinical effectiveness and short- and medium-term surgery complications. ${ }^{18}$ There were 259 instances of very low-quality evidence across the statements and only one high-quality evidence statement in one RCT. Overall, interpretation of the results was limited by the quality of the data, and the trials were too short to inform long-term complications and were not able to detect serious adverse events or postoperative complications. For POP, NICE reported 46 studies of short-term complications following surgery, 24 for midterm complications, and 17 on long-term complications. ${ }^{18}$ Only one instance of high-quality evidence was reported. For POP with SUI, four articles reported data from three trials. Because of the lack of evidence, NICE recommended that it is essential to explain this gap in longer-term outcomes to women prior to treatment.

There has been a consistent lack of long-term evidence over the use of surgical mesh. NICE, Cochrane, and the FDA have reported a lack of long-term outcome data. In the Cochrane review on surgery for women with POP with or without SUI, 19 RCTs reported that "adverse events 
were infrequently reported in all studies". ${ }^{19}$ A further Cochrane review of mid-urethral sling operations for SUI in women including 81 studies reported that the occurrence of problems with sexual intercourse involving pain was low, in contrast to our findings. The review, however, reported only ten trials assessed this outcome with followup that spanned six to 24 months. ${ }^{20}$

Other study designs have also suggested poor health outcomes. A large Canadian database cohort study found higher risks of depression and self-harm in women who required a surgical intervention for complications after a mid-urethral mesh sling procedure $;^{21}$ a retrospective case series review found a high prevalence of psychiatric and chronic pain conditions in patients undergoing mesh removal; ${ }^{22}$ and a qualitative study of women presenting to a tertiary care clinic with complications relating to vaginal mesh found that these complications caused both physical and emotional pain. ${ }^{23}$ The latter study suggested that women's experiences followed different trajectories: some women experienced worsening health problems, anxiety and desperation, others who once considered themselves healthy, believed themselves unhealthy and adjusted their views accordingly, and a minority of women described a return to health. This concept could plausibly aid the interpretation of our results.

To date, there has been a lack of data in primary care and long-term follow-up, and hence the need for this study.

\section{Strength and Limitations}

This is a large-scale analysis of high-quality data, representative of the UK population; ${ }^{12}$ however, we were only able to study women in English practices as linkage is required to obtain data on our primary exposure, mesh surgery. Previous studies ${ }^{24}$ have shown that age distributions of patients with and without linkage are similar and, since everyone living in England is entitled to access national health services, we believe selection bias is minimal.

Mesh surgery status should be well recorded in HES data, but there may be some misclassification of exposure status if patients have mesh insertion surgery prior to registering with the CPRD practice contributing data. Given that it is a relatively major surgery, it may be coded retrospectively. We also used codes for repair/ removal of mesh devices to assess exposure status. It is plausible that different mesh devices may have different complication rates; however, information on the specific type of mesh device is not available. There is often a lag between allocating a specific code to a procedure and the procedure coming into use. Codes for mesh surgery for SUI (tension-free vaginal tape and transobturator tapes) were introduced in April 2006. ${ }^{1}$ Prior to this date more general codes were used, and we therefore may have missed some women who had surgery and misclassified them as unexposed to mesh surgery. The surgeon's preference and training may also affect the association between surgery and outcomes.

A major limitation of this study is that those who choose to undergo mesh surgery may differ from those who do not, including by disease severity. Consistent with existing literature, ${ }^{25,26}$ the prevalence of a previous history of depression, anxiety and self-harm and sexual dysfunction was greater in those who had mesh surgery. Our multivariate subgroup analyses were considered hypothesis generating, with the aim of identifying factors that may increase the risk of patient outcomes. Our descriptive comparisons between patients who did and did not have mesh devices fitted may be particularly vulnerable to confounding by indication, but we still feel that this comparison is worth including to give some indication of rates of each outcome in a group of patients who may have been eligible for a mesh device. Sensitivity analyses including women with mesh surgery at or after study entry showed similar results. While there is no evidence of an association between our negative control outcome, asthma consultation rates, and mesh surgery for POP, our analyses for women with SUI suggest that our results are subject to residual confounding.

Depression, anxiety and self-harm, and sexual dysfunction may have been under ascertained, as symptom data is known to not be well recorded: some patients with these conditions will not be diagnosed, some will not have their diagnosis recorded, ${ }^{27}$ and some patients may not report symptoms We used published strategies and code lists that included both diagnostic and prescription codes to try to minimise this. ${ }^{28}$ Given the media exposure to mesh surgery, sexual dysfunction recording in particular may also be subject to reporting bias.

\section{Implications for Clinicians and Policymakers}

Our results suggest that careful consideration of the benefits and risks of mesh surgery for women with SUI or POP 
on an individual basis is required. The IMMDS review, published in 2020, ${ }^{1}$ reported "the system does not know the true long-term complication rate for pelvic mesh procedures" and that it "is impossible to know how many women would have chosen a different form of treatment a different care pathway - if only they had been given the information they needed to make a fully-informed choice." We consider the primary care data presented here essential to informed decision-making.

Recommendation 7 in the IMMDS review ${ }^{1}$ sets out the need for a central patient-identifiable database. The implantation of devices at the time of the operation should then "be linked to specifically created registers to research and audit the outcomes both in terms of the device safety and patient reported outcomes measures." We consider the linking of the data to primary care essential and that the data analysis and dissemination be done in real time to facilitate timely decision-making.

\section{Conclusions}

In a large cohort of women in primary care, rates of antibiotic prescriptions were increased in those who underwent mesh surgery for SUI and POP; rates of depression, anxiety, and self-harm, sexual dysfunction and opioids prescriptions were increased in those who had no history of these outcomes and underwent SUI or POP mesh surgery; rates of depression, anxiety and self-harm were lower in those with a previous history who underwent SUI or POP mesh surgery; rates of opioid use were lower in women with a previous history who underwent POP mesh surgery. While there is evidence that results are subject to residual confounding, careful consideration of the benefits and risks of mesh surgery for women with SUI or POP on an individual basis is required, and the linking of registers and auditing of clinical outcomes for mesh is essential to inform decision-making.

\section{Abbreviations}

SUI, stress urinary incontinence; POP, pelvic organ prolapse; CPRD, Clinical Practice Research Datalink; HES, Hospital Episodes Statistics; ONS, Office for National Statistics; IMD, Index of Multiple Deprivation socioeconomic data; NNT, numbers needed to treat; NNH, numbers needed to harm; ISAC, Independent Scientific Advisory Committee; HR, Hazard ratio; IRR, Incidence rate ratio; 95\% CI, 95\% confidence interval; IMMDS, Independent Medicines and Medical Devices Safety Review.

\section{Transparency}

The lead author (EM) affirms that the manuscript is an honest, accurate, and transparent account of the study being reported; that no important aspects of the study have been omitted; and that any discrepancies from the study as planned (and, if relevant, registered) have been explained.

\section{Patient or User Group Involvement Statement}

Patient representatives from patient advocacy group, Sling the Mesh, were involved (via conference call) with the protocol, research question, objectives, and outcome measures of the study to ensure they were patient-specific, appropriate, and relevant. This study uses routinely collected data, so no recruitment was required.

\section{Data Sharing Statement}

To guarantee the confidentiality of personal and health information, only the authors have had access to the data during the study in accordance with the relevant licence agreements. CPRD-linked data were provided under a license that does not permit sharing.

\section{Acknowledgments}

All authors contributed to data analysis, drafting or revising the article, gave final approval for the version to be published, agreed to the submitted journal, and agreed to be accountable for all aspects of the work.

\section{Funding}

This work was funded by the NIHR School for Primary Care Research [project no. 438, round FR17].

\section{Disclosure}

All authors have completed the ICMJE uniform disclosure form at www.icmje.org/coi disclosure.pdf. EM has no conflicts of interest. SLF was supported by the NIHR Biomedical Research Centre (Oxford) and NIHR Applied Research Collaboration Oxford and Thames Valley during the conduct of the study, but outside the submitted work. CK is currently supported by a Wellcome Trust/Royal Society Sir Henry Dale Fellowship, but outside the submitted work. GCR was financially supported by the National Institute of Health Research (NIHR) School for Primary Care Research (SPCR), the Naji Foundation, and the Rotary Foundation to study for a Doctor of Philosophy, but no longer has any 
conflicts of interest. $\mathrm{CH}$ holds grant funding from the NIHR School of Primary Care Research Evidence Synthesis Working Group [Project 390], the NIHR BRC Oxford and the World Health Organization for a series of Living rapid review on the modes of transmission of SARs-CoV-2. $\mathrm{CH}$ has received financial remuneration from an asbestos case and given legal advice on mesh and hormone pregnancy tests cases. He has received expenses and fees for his media work including occasional payments from BBC Radio 4 Inside Health and The Spectator. He receives expenses for teaching EBM and is also paid for his GP work in NHS out of hours (contract Oxford Health NHS Foundation Trust). He has also received income from the publication of a series of toolkit books and for appraising treatment recommendations in non-NHS settings. He is Director of CEBM and an NIHR Senior Investigator and an advisor to Collateral Global. The authors report no other conflicts of interest in this work.

\section{References}

1. First do no harm: the report of the independent medicines and medical devices safety review. Crown copyright; 2020.

2. Maher C, Feiner B, Baessler K, Christmann-Schmid C, Haya N, Brown J. Surgery for women with anterior compartment prolapse. Cochrane Database Syst Rev. 2016;11:CD004014. doi:10.1002/ 14651858.CD004014.pub6

3. Nambiar A, Cody JD, Jeffery ST. Single-incision sling operations for urinary incontinence in women. In: Nambiar A, editor. Cochrane Database of Systematic Reviews. Chichester, UK: John Wiley \& Sons, Ltd; 2014:CD008709. doi:10.1002/14651858.CD008709.pub2

4. Abed H, Rahn DD, Lowenstein L, et al. Incidence and management of graft erosion, wound granulation, and dyspareunia following vaginal prolapse repair with graft materials: a systematic review. Int Urogynecol J. 2011;22(7):789-798. doi:10.1007/s00192-011-1384-5

5. Keltie K, Elneil S, Monga A, et al. Complications following vaginal mesh procedures for stress urinary incontinence: an 8 year study of 92,246 women. Sci Rep. 2017;7(1):12015. doi:10.1038/s41598-017-11821-w

6. Akre J. Jury awards $\$ 26.7$ million to four women injured by Boston Scientific pelvic mesh! - mesh medical device news desk; 2014 Available from: https://www.meshmedicaldevicenewsdesk.com/break ing-news-jury-decides-28-million-for-four-women-injured-by-boston -scientific-pelvic-mesh/. Accessed July 22, 2019.

7. Sanghani R. Why hundreds of women are suing the NHS over vaginal mesh surgery: "It felt like I had cut glass inside me"; 2017. Avaialble from: https://www.telegraph.co.uk/health-fitness/body/hun dreds-women-suing-nhs-vaginal-mesh-surgery-felt-like-had/. Accessed July 22, 2019.

8. The Scottish Government. The Scottish independent review of the use, safety and efficacy of transvaginal mesh implants in the treatment of stress urinary incontinence and pelvic organ prolapse in women: final report. Edinburgh; 2017.

9. Wise J. Surgical mesh for stress urinary incontinence to be halted immediately in England. BMJ. 2018;362:k3035. doi:10.1136/bmj. k3035

10. Heneghan C. What next for transvaginal mesh? - The BMJ. The BMJ Opinion; 2019. Available from: https://blogs.bmj.com/bmj/2019/06/ 05/carl-heneghan-what-next-for-transvaginal-mesh/. Accessed July $16,2019$.
11. Gurol-Urganci I, Geary RS, Mamza JB, et al. Long-term rate of mesh sling removal following midurethral mesh sling insertion among women with stress urinary incontinence. JAMA. 2018;320(16):1659. doi:10.1001/jama.2018.14997

12. Herrett E, Gallagher AM, Bhaskaran K, et al. Data resource profile: Clinical Practice Research Datalink (CPRD). Int J Epidemiol. 2015;44(3):827-836. doi:10.1093/ije/dyv098

13. Austin PC. Absolute risk reductions and numbers needed to treat can be obtained from adjusted survival models for time-to-event outcomes. J Clin Epidemiol. 2010;63(1):46-55. doi:10.1016/j. jclinepi.2009.03.012

14. Brand J, van Buuren S, le Cessie S, van den Hout W. Combining multiple imputation and bootstrap in the analysis of cost-effectiveness trial data. Stat Med. 2019;38(2):210-220. doi:10.1002/sim.7956

15. Suissa S. Number needed to treat: enigmatic results for exacerbations in COPD. Eur Respir J. 2016;47(1):354-355. doi:10.1183/ 13993003.01449-2015

16. Rubin DB, Schenker N. Multiple imputation in health-care databases: an overview and some applications. Stat Med. 1991;10(4):585-598. doi:10.1002/sim.4780100410

17. NICE. Transvaginal mesh repair of anterior or posterior vaginal wall prolapse IPG599; 2017.

18. NICE. Urinary incontinence and pelvic organ prolapse in women: management NG123; 2019.

19. Ford AA, Rogerson L, Cody JD, Ogah J. Mid-urethral sling operations for stress urinary incontinence in women. Cochrane Database Syst Rev. 2015;7:CD006375. doi:10.1002/14651858.CD006375.pub3

20. Baessler K, Christmann-Schmid C, Maher C, Haya N, Crawford TJ, Brown J. Surgery for women with pelvic organ prolapse with or without stress urinary incontinence. Cochrane Database Syst Rev. 2018;8(8):CD013108. doi:10.1002/14651858.CD013108

21. Welk B, Reid J, Kelly E, Wu YM. Association of transvaginal mesh complications with the risk of new-onset depression or self-harm in women with a midurethral sling. JAMA Surg. 2019;154(4):358-360. doi:10.1001/jamasurg.2018.4644

22. Blau EK, Adelstein SA, Amin KA, et al. Tobacco use, immunosuppressive, chronic pain, and psychiatric conditions are prevalent in women with symptomatic mesh complications undergoing mesh removal surgery. Investig Clin Urol. 2020;61(Suppl 1):S57-S63. doi:10.4111/icu.2020.61.S1.S57

23. Dunn GE, Hansen BL, Egger MJ, et al. Changed women: the long-term impact of vaginal mesh complications. Female Pelvic Med Reconstr Surg. 2014;20(3):131-136. doi:10.1097/ SPV.0000000000000083

24. Lay-Flurrie S, Sheppard J, Stevens R, et al. Impact of changes to national hypertension guidelines on hypertension management and outcomes in the United Kingdom. Hypertension. 2020;75 (2):356-364. doi:10.1161/HYPERTENSIONAHA.119.13926

25. Coyne KS, Wein A, Nicholson S, Kvasz M, Chen C-I, Milsom I. Comorbidities and personal burden of urgency urinary incontinence: a systematic review. Int J Clin Pract. 2013;67(10):1015-1033. doi:10.1111/ijcp.12164

26. Maher C, Feiner B, Baessler K, Glazener CM, Hagen S, Glazener CM. Surgical management of pelvic organ prolapse in women. In: Maher $\mathrm{C}$, editor. Cochrane Database of Systematic Reviews. Chichester, UK: John Wiley \& Sons, Ltd; 2010: CD004014. doi:10.1002/14651858.CD004014.pub4

27. Kendrick T, Stuart B, Newell C, Geraghty A, Moore M. Changes in rates of recorded depression in English primary care 2003-2013: time trend analyses of effects of the economic recession, and the GP contract quality outcomes framework. $J$ Affect Disord. 2015;180:68-78. doi:10.1016/j.jad.2015.03.040

28. Primary Care Unit University of Cambridge. CPRD@ Cambridge codes Lists (GOLD) DEP152 and DEP153. Available from: https:// www.phpc.cam.ac.uk/pcu/research/research-groups/crmh/cprd_cam/ codelists/v11/. Accessed January 22, 2021. 


\section{Publish your work in this journal}

Clinical Epidemiology is an international, peer-reviewed, open access, online journal focusing on disease and drug epidemiology, identification of risk factors and screening procedures to develop optimal preventative initiatives and programs. Specific topics include: diagnosis, prognosis, treatment, screening, prevention, risk factor modification,

Submit your manuscript here: https://www.dovepress.com/clinical-epidemiology-journal systematic reviews, risk \& safety of medical interventions, epidemiology \& biostatistical methods, and evaluation of guidelines, translational medicine, health policies \& economic evaluations. The manuscript management system is completely online and includes a very quick and fair peer-review system, which is all easy to use. 